\title{
Report and Recommendation of Implementation Research-Based Learning in Improving Combinatorial Thinking Skills embedded in STEM Parachute Design Activities Assisted by CCR (Cloud Classroom)
}

\author{
Z R Ridlo ${ }^{1, *}$, Dafik $^{2}$, C I W Nugroho ${ }^{3}$ \\ ${ }^{1}$ Department of Natural Science Education, Faculty of Teacher Training and Education, University of Jember, Indonesia \\ ${ }^{2}$ Department of Mathematics Education, Faculty of Teacher Training and Education, University of Jember, Indonesia \\ ${ }^{3}$ Department of Physics Education, Faculty of Teacher Training and Education, University of Jember, Indonesia
}

Received January 3, 2020; Revised March 11, 2020; Accepted March 19, 2020

Copyright $\bigcirc 2020$ by authors, all rights reserved. Authors agree that this article remains permanently open access under the terms of the Creative Commons Attribution License 4.0 International License

\begin{abstract}
The research aims to compare the advanced class (experimental class) and traditional class with the traditional teaching method. This research is concerned with STEM activity in parachute design. The experiment class applies research-based learning methods integrated with Cloud Classroom (CCR), and the Traditional class is taught using conventional teacher talk or explanation. This research used triangulation methods, quantitative, and qualitative methods. The data analysis of the post-test indicated a value of sig (2-tailed) 0.00 where $\mathrm{p} \leq 0.05$, which implied the student achievement on combinatorial thinking skills criteria in the experimental class was better than that in the control class. The combinatorial thinking skills in experimental class after implementation of RBL was that $16 \%$ student were categorized in a low level of combinatorial thinking skills, 39\% in medium level and $45 \%$ of the student was at the high level of combinatorial thinking skills. The activity of students in the experimental class reached $35 \%$ as the highest activity for very active activity, $27 \%$ active, hesitate $27 \%$, inactive $6 \%$, and very inactive $5 \%$. Based on this result, the implementation of research-based learning integrated with $\mathrm{CCR}$ is proven effective in improving student Combinatorial Thinking skills in STEM activity for parachute design.
\end{abstract}

Keywords STEM Activity, Parachute Design, Research-Based Learning, Combinatorial Thinking Skills, Cloud Classroom

\section{Introduction}

The development of increasingly advanced technology requires a person to master various kinds of scientific disciplines in solving problems. Uniquely, in solving this problem, each person has their way that is felt easiest. This implies that there is a specific pattern of resolution done by someone in dealing with problems. This ability is called Combinatorial Thinking Skills. The process of thinking combination is part of mathematical thinking [1]. On the other side, the ability to think mathematically is played by the ability of generalization and abstraction [2]. Combinatorial Thinking Skills mean that, when faced with a problem, a student tends to solve the problem with various forms of solutions. There are five indicators and several sub-indicators that can be used as a reference to find someone thinking in combination [3][4]. The first indicator is to identify some problems, with sub-indicators (a) identifying the characteristics of the problem and (b) applying them in some cases. The second indicator is to understand the pattern of the problem, with sub-indicators (a) identifying the problem solution, and (b) expanding the solution of the problem by taking into account several possibilities. The third indicator is applying mathematical patterns, with sub-indicators (a) applying mathematical patterns, (b) doing cardinality calculations, and (c) developing a settlement algorithm. The fourth indicator is mathematical proof with sub-indicators (a) doing some argument calculation, (b) doing algorithmic testing, (c) developing bijection, (d) doing testing on bijection, and (e) implementing inductive, deductive and qualitative verification. The fifth indicator is considering several other problem combinations, with sub-indicators (a) interpreting the problem, (b) proposing several related problems, (c) knowing the new combination problem, and (d) finding potential applications in the solution [1][5]. In this research, 
we develop combinatorial thinking criteria into STEM activity according to Science, Technology, Engineering, and Mathematics section.

The Research-Based Learning (RBL) model of teaching integrates research activities in learning activities [6]. In this research, we use the RBL model integrated with STEM activity for Science, Technology, Engineering and Mathematics (STEM) to improve students' Combinatorial Thinking Skills. This is because there are still many students who have a good scientific foundation but are lacking in applying their knowledge [7]. STEM is a combination of several scientific disciplines, and on the other side, interacting with STEM is an important component for learning experience [8]. STEM integration is defined as a combination of science, technology, engineering and mathematics in the hope that it can (1) depend on students 'understanding of each discipline in a contextual manner, (2) broaden students' understanding of each discipline in the context of STEM that is culturally relevant and (3) increase students' interest in each discipline by presenting several avenues that students can take to explore each STEM field [9]. In this case, students' responses to the STEM approach hold an important key in learning. Some predictors that can affect students' perceptions and attitudes towards this approach are motivation, experience, and self-efficacy [10]. Therefore, in learning which uses the STEM approach, the implementation of problem-based learning and projects are suggested because the real situation can increase student motivation in participating in learning and can also increase student interest, achievement, and perseverance [11]. The RBL model improves student academics and also builds skills in applying previously acquired theories into practice. So, students can fully understand what they are learning [10]. In previous research, the RBL learning model can increase student interest in learning the content provided, make them more active, more creative, and think more critically and can improve learning outcomes [11] [12] [13]. An essential part of this model is that students must know the theories related to the object of research, including Science (Applying principles of relationship between motion, force, and momentum), Technology (selecting appropriate technology to solve problems in parachute design), Engineering (using iterative research to solve process and selecting appropriate tools to solve the problems), and Mathematics (solving physical equation in physical section, and using circle formula and Pythagorean theorem to design parachute [14]. There are several steps that must be done by students in conducting research activity in the learning process which explain in Figure 1. In the beginning, students must know what they are going to research and the theory based on relevant sources. After that, initial observations are made in the field by making some evidence in the form of photos or videos. Some other supporting evidence can also be taken into account. Hopefully, students have a picture of completion and consider the results of their deductions using some supporting evidence. So students can interpret the results of research that has been done. Next, students design a solution to a related problem. From these results, a conclusion is drawn about the actions they took and reports what was obtained. Another important part of this learning model is that students need help from friends formed in a study group. This means that students must work in teams composed of two or more persons who are involved in conducting a study, so that collaboration in teams is needed. The purpose of cooperative learning is to create a situation where the success of individuals in the group is indicated as understanding the material, solving problems, and discussion about finding solutions [15].

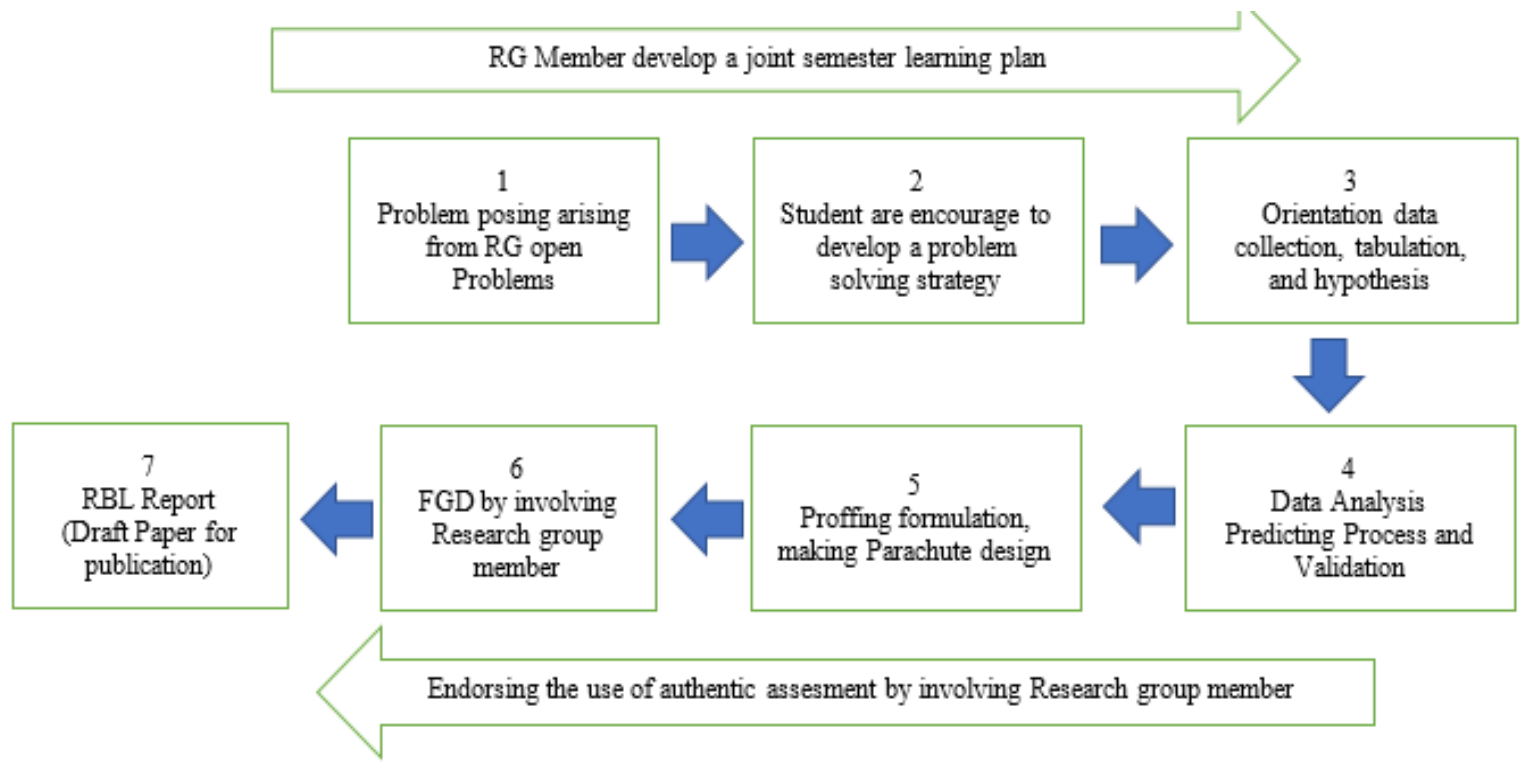

Figure 1. The stages of implementation RBL in STEM activity (Parachute Design) 
In a parachute design project, the STEM approach can be used as a solution to make students understand what must be done to solve a problem because STEM integration offers the best way for students to learn a situation in the real world. It is not in the form of parts that must be considered one by one [16]. The effective implementation of the STEM approach does not only focus on scientific content but can also arouse curiosity and cognitive reasoning skills accompanied by relevant evidence and understanding and appreciation of the scientific research process [17]. This can be seen in the integration of research activity to solve the problem of students in making good parachute designs. This is because the problems that must be faced by students start from the selected design of parachute. In STEM activity, an indicator of a good parachute is that we try to drop an egg with a parachute from the third floor of building into the ground without breaking an egg.

\section{Materials and Methods}

This research was conducted to compare traditional learning with learning using the RBL model in STEM activities for parachute design. In its implementation, the study applied qualitative and quantitative methods. Quantitative methods are used to analyze student work in solving problems regarding the STEM activities for parachute design after being subject to the RBL learning model. Qualitative methods are used to analyze data from the results of interviews conducted with students to find out their opinions about RBL. The independent variable of this study is the RBL learning model. The dependent variable is student learning outcomes. After students completed the task, interviews were conducted with the experimental class to find out their opinions about the research-based learning model. The research design used two classes composed of control classes and experimental classes selected by purposive random sampling and examined using a pre-test and post-test using the following design.

Table 1. Design of Research using Mix Methods

\begin{tabular}{|c|c|c|c|}
\hline Group & Pre-test & Treatment & Post-test \\
\hline $\begin{array}{c}\text { Control Class } \\
\mathbf{n}=40 \text { Student } \\
\text { (14 males and 26 females) }\end{array}$ & $O_{1}$ & - & $O_{2}$ \\
\hline $\begin{array}{c}\text { Experiment Class } \\
\text { n=40 Student } \\
\text { (14 males and 26 females) }\end{array}$ & $O_{3}$ & $\mathrm{X}$ & $O_{4}$ \\
\hline
\end{tabular}

$\mathrm{R}=$ both experimental and control class were chosen randomly

$\mathrm{O}_{1} \& \mathrm{O}_{3}=$ both groups were examined using a pre-test in order to find out their combinatorial thinking skills, which was expected to be at the same level.

$\mathrm{O}_{2}=$ the post-test result of the control class.

$\mathrm{O}_{4}=$ the post-test result of the experiment class [18].

In the design of this study is mix methods which show in Table 1, the two classes used were randomly selected (R). One class is subject to the RBL (X) class, while the other class uses traditional learning. The class subject to a treatment is called the experimental class, while the non-treated class is called the control class. The effect of the treatment is shown $\left(\mathrm{O}_{2}: \mathrm{O}_{4}\right)$ and then analyzed using a t-test, as stated by [18] Figure 2 shows the triangulation model. That picture showed qualitative data with quantitative data to determine the effect of learning model RBL on resolving problems in STEM activities courses. 


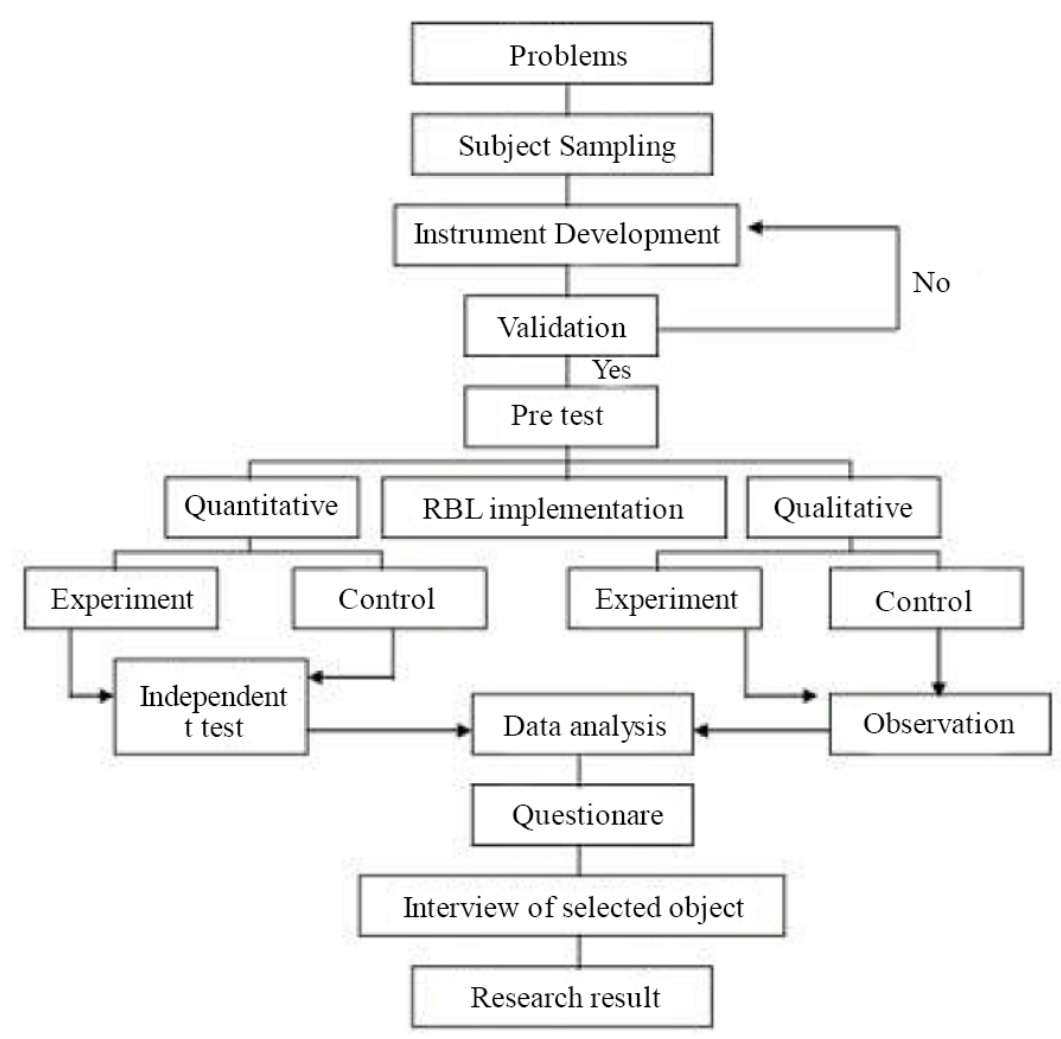

Figure 2. The model of the triangulation method [18]

\subsection{Population}

In this study, the people involved were fourth-semester students who studied the implementation of STEM in elementary students. All students were from faculty of teacher training and education at the University of Jember. Next, class selection was done through cluster sampling to select two classes. The total number of students in this study was 80 students, with ages ranging from 19-20 years. There were 40 students in the experimental class consisting of 18 males and 22 females. In the control class, there were 40 students consisting of 15 males and 25 females. Data were taken from April to July 2019. To retrieve data, there were several instruments provided. These instruments were tasks, interviews, questionnaires, and observation sheets. Instruments in the form of the task were used to find out the extent of students in understanding the concept of STEM activities for parachute design. The observation sheet was used to determine the level of student activity. Interviews and questionnaires are used to determine students' opinions regarding research-based learning models.

\subsection{Instruments}

The instruments used in this study consisted of student tasks integrated with CCR (Cloud Classroom), observation sheets, interviews, and questionnaires. The student task contained questions about STEM and how to develop a parachute design. Interviews and questionnaires were only given to the experimental class, which consisted of several question items to express the qualitative result. The observation sheet employed Likert scale Very Active (Score 5), Active (Score 4), Hesitate (Score 3), Inactive (Score 2), Very Inactive (Score 1). The instrument sheet was validated by an expert in STEM education.

\subsection{Tasks}

In this study, students in both classes were given tasks about parachute design including STEM activities. In the experimental class, research-based learning is applied. While in the controlled class, teaching still uses conventional methods. The application of STEM in the design of parachutes can be seen in each of its fields. The field of science requires students to know the concepts of physics regarding the workings of a parachute. The field of technology requires students to find out information about the development of parachutes. The field of engineering requires students to design an efficient parachute. The field of mathematics requires students to carry out calculations carefully.

The science and mathematics concept in the development of parachute design is physics and calculus concept. The most important physics concepts that students should understand are (1) kinematics of free-fall motion, (2) the concept of dynamics of free-fall motion, and (3) the 
concept of air friction. Here are some concepts and equations to understanding science concepts:

\subsubsection{Kinematics of Free-Fall Motion in Ideal Conditions}

Kinematics is subject in elementary physics focuses on motion without analysis about the cause of the motion. There are some concepts in physics like velocity, acceleration (gravitational acceleration), time, and high.

$$
\begin{gathered}
\int_{v_{0}}^{v_{t}} d v=\int_{0}^{t} a d t \rightarrow v=a t \\
\int_{0}^{h} d x=\int_{0}^{t} v_{0} d t+\int_{0}^{t} a t d t \rightarrow h=v_{0} t+\frac{1}{2} a t^{2}
\end{gathered}
$$

Because it is a free-fall motion $\mathrm{v}_{0}=0$, equations (1) and (2) can produce a new equation in the form

$$
v_{t}^{2}=v_{0}^{2}+2 a h
$$

Equation 1, 2, and 3 in acceleration are modified into gravitational acceleration because, in free-fall conditions, gravitational acceleration exerts in a parachute. Modification of formulation is written in equation (4), (5), and (6)below.

$$
\begin{gathered}
\int_{0}^{v_{t}} d v=\int_{0}^{t} g d t \rightarrow v=g t \\
\int_{0}^{h} d x=\int_{0}^{t} v_{0} d t+\int_{0}^{t} g t d t \rightarrow h=v_{0} t+\frac{1}{2} g t^{2} \\
v_{t}^{2}=v_{0}^{2}+2 g h
\end{gathered}
$$

Equation (6) in free fall condition without initial velocity $(0 \mathrm{~m} / \mathrm{s})$ is modified into equation (7) and (8), and equation (8) expresses velocity of the parachute.

$$
\begin{gathered}
v_{t}^{2}=2 g h \\
v_{t}=\sqrt{2 g h}
\end{gathered}
$$

2.3.2. The Dynamics of Free-Fall Motion If Air Resistance Is Proportional to the Velocity of the Object

$$
\begin{gathered}
m \frac{d v}{d t}=-m g-b v \\
\int_{0}^{v} \frac{d v}{v+\frac{m g}{b}}=-\frac{b t}{m} \\
x=\frac{m^{2} g}{b}\left(1-\frac{b t}{m}-e^{-b t / m}\right)
\end{gathered}
$$

Technology in STEM activities is analyzed and visualizes the data from the experiment to create information and make model processes, entities, and their relationships using structured data. The data interpretation is made using the software, for example, Ms. Excel, Matlab, CCR, etc.

Engineering in STEM activity is concerned with goals to generate, develop, and test design of parachute to create the best design solution to the problems of soft landing of an object (egg) from height $10 \mathrm{~m}$. Part of design is investigated and making judgment about how the characteristics, properties of materials, length of parachute ropes, shape of parachute, give effect on parachute landing. Properties of materials are combined with force, motion, and energy to create engineered solutions and apply the design of thinking according to creativity and innovation to develop, modify and communicate design ideas. STEM parachute design is shown in Figure 3 below.



Figure 3. Engineering steps in STEM Parachute Design 


\subsubsection{The curriculum analysis related to STEM concept}

The curriculum analysis related to the STEM concept in teaching and learning activity started with the integration between Science concept which is related to Physics Concept. Technology is related to software and computer programming to make simulation of freefall motion and data analysis. Engineering is about the psychomotor activity to design parachute effectively and efficiently, and Mathematics into one of the topics in an elementary related to a science concept. The purpose of this course was to develop student capability in mathematics and science. Parachute Design was chosen as a topic for student STEM activity learning because we hope the student can improve capability in science and mathematics in one set of learning activity.

\subsection{Finding}

The teaching and learning process gives the result of implementation RBL in STEM activities in the Experiment class compared with the control class that uses traditional method analysis using an independent sample t-test. The result of the pretest score from control and experiment class is a normal distribution, which means the class is homogenous. The total number of students in both classes is 80 students (40 student experiment class and 40 student control class). Further analysis is explained by statistic software (SPSS). The result of the Pre-test score indicates significant differences between the control class and experiment class, as seen in Table 2.

The significance value serves as the basis to analyze and get a decision from the data displayed. The significant value is set at $5 \%$ or 0.05 . The average achievement test in the control class is 56.87 , with a Standart deviation of 8.52504, and the average achievement test in the experimental class is 59.72 , with a standard deviation of 3.71406. The different means of a control class and experimental class are not significant.

Table 3 shows the analysis of the pretest from the experimental class and control class. The result of the t-test indicates the value od significant (2-tailed) 0.056 with criteria of significant value is 0.05 . According to the criteria of homogeneity, statistic means the two classes are homogenous because the value of sig (2-tailed) is bigger than 0.05 .

Table 2. The table display pre-test result and mean value control class and experiment class

\begin{tabular}{|c|c|c|c|c|}
\hline Group & N & Mean & Std. Deviation & Std. Error Mean \\
\hline $\begin{array}{c}\text { The Pre-test score of Control Class } \\
\text { (40 Student) }\end{array}$ & 40 & 56.87 & 8.52504 & 1.34793 \\
\hline $\begin{array}{c}\text { The Pre-test score of Experiment Class } \\
\text { (40 Student) }\end{array}$ & 40 & 59.72 & 3.71406 & 0.58724 \\
\hline
\end{tabular}

Table 3. The comparison of pre-test results and mean value control class and experiment class

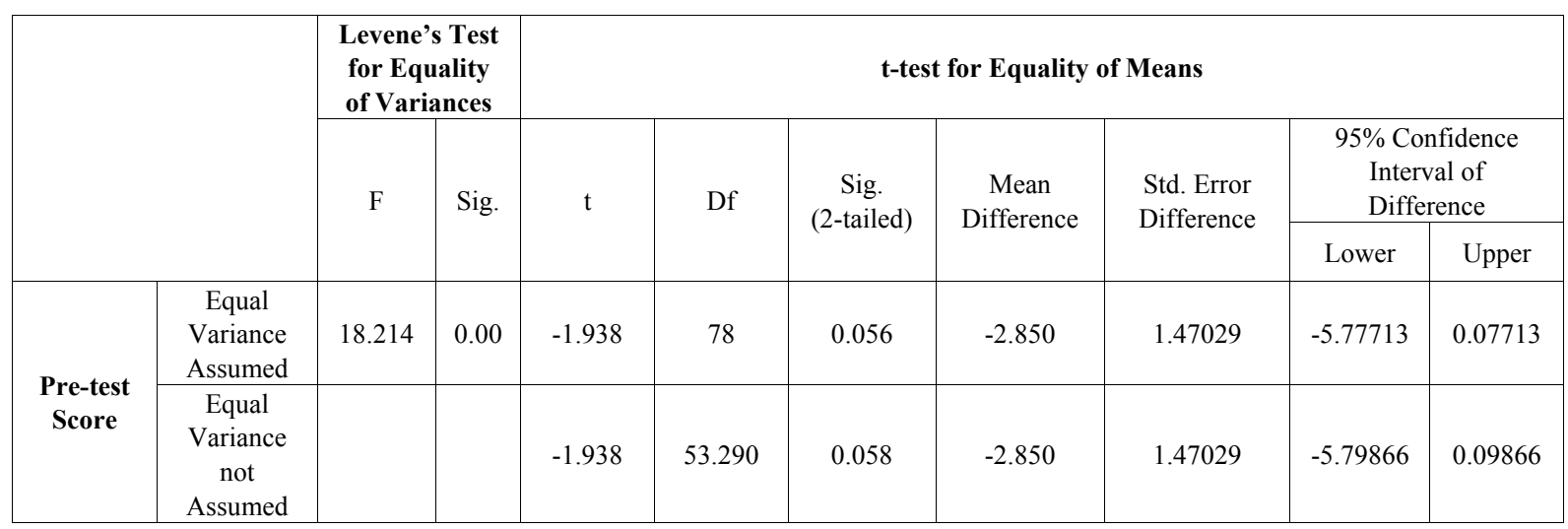




\subsection{Post-test}

The table below (Table 4.) displays a comparison of post-test results and the mean value from the control class and experiment class. Mean from control class reach 73.5750 with Standart Deviation value 5.887350 , while the mean of experiment class reaches 80.025 with Standart Deviation value 3.96451. The information from Table 5 shows that there is a significant value between two classes indicated with the value of $t$ in Levene's Test score -5.747 , according to the value of $\mathrm{p}<0.005$

Table 4. Comparison of post-test results from the control class and experiment class

\begin{tabular}{|c|c|c|c|c|}
\hline Group & N & Mean & Std. Deviation & Std. Error Mean \\
\hline $\begin{array}{c}\text { The Post-test score of Control Class } \\
\text { (40 Student) }\end{array}$ & 40 & 73.5750 & 5.88735 & .93087 \\
\hline $\begin{array}{c}\text { The Post-test score of Experiment Class } \\
\text { (40 Student) }\end{array}$ & 40 & 80.0250 & 3.96451 & .62684 \\
\hline
\end{tabular}

Table 5. The comparison of post-test score between experimental class and control class based on independent sample t-test

\begin{tabular}{|c|c|c|c|c|c|c|c|c|c|c|}
\hline & \multicolumn{2}{|c|}{$\begin{array}{l}\text { Levene's Test } \\
\text { for Equality of } \\
\text { Variances }\end{array}$} & \multicolumn{7}{|c|}{ t-test for Equality of Means } \\
\hline & & \multirow{2}{*}{$\mathrm{F}$} & \multirow{2}{*}{ Sig. } & \multirow[t]{2}{*}{$\mathrm{t}$} & \multirow{2}{*}{ Df } & \multirow{2}{*}{$\begin{array}{c}\text { Sig. } \\
\text { (2-tailed) }\end{array}$} & \multirow{2}{*}{$\begin{array}{c}\text { Mean } \\
\text { Difference }\end{array}$} & \multirow{2}{*}{$\begin{array}{l}\text { Std. Error } \\
\text { Difference }\end{array}$} & \multicolumn{2}{|c|}{$\begin{array}{c}95 \% \text { Confidence Interval } \\
\text { of Difference }\end{array}$} \\
\hline & & & & & & & & & Lower & Upper \\
\hline \multirow{2}{*}{$\begin{array}{l}\text { Post-test } \\
\text { Score }\end{array}$} & $\begin{array}{c}\text { Equal } \\
\text { Variance } \\
\text { Assumed }\end{array}$ & 7.817 & .007 & -5.747 & 78 & .000 & -6.45000 & 1.12225 & -8.68424 & -4.21576 \\
\hline & $\begin{array}{c}\text { Equal } \\
\text { Variance } \\
\text { not } \\
\text { Assumed }\end{array}$ & & & -5.747 & 68.337 & 000 & -6.45000 & 1.12225 & -8.68922 & -4.21078 \\
\hline
\end{tabular}

Table 5. also shows the result of the independent sample t-test indicating the significant value of $0.000(p \leq 0.05)$. Thus, it is significant. The findings conclude that two classes have differences in terms of student combinatorial thinking test after implementation of RBL is STEM activity to design parachute.

The student activity in the experimental class is analyzed by ten observers using Likert scale student activity spread into five categories very active (score 5), active (score 4), hesitate (score 3), inactive (score 2), and very inactive (score 1). The total result of observation student activity is shown in the Figure below.



Figure 4. The student activity in experimental class during the implementation of the RBL Method 
Figure 4 shows students' activity from the experimental class consists of 40 students. The highest score of observation is $35 \%$ of the total student, which indicates during Research-Based Learning implementation students very active to cooperate with learning process according to combinatorial thinking skills. The second criteria of student activity are $27 \%$ is active level, $27 \%$ are in the hesitate, $6 \%$ in inactive, and $5 \%$ are very inactive. The conclusion is that the implementation of the RBL method is very effective in a STEM activity in parachute design problems. STEM activity in parachute design needs a lot of information about a fact, concept, and theory integrated with STEM information according to Science (Physics), Technology (data interpretation), Engineering (development and modification design of parachute), and
Mathematics (calculation related to science concept and data interpretation), Physics is part of science concept including gravitational acceleration, gravitational force, air friction, and velocity of parachute. The mathematics section included formulation with mathematics instruction.

The result of the pretest score of both class shows the initial capability of both control class and experimental class according to homogeneity and normality distribution of both class. In Figure 5 and Figure 6, the Initial capability of combinatorial thinking skills in the control class is $79 \%$ in low combinatorial thinking skills and $21 \%$ in medium criteria. Combinatorial thinking skills in experimental class data are found at $21 \%$ of students categorized in medium combinatorial thinking skills and $79 \%$ in the low category of combinatorial thinking skills.

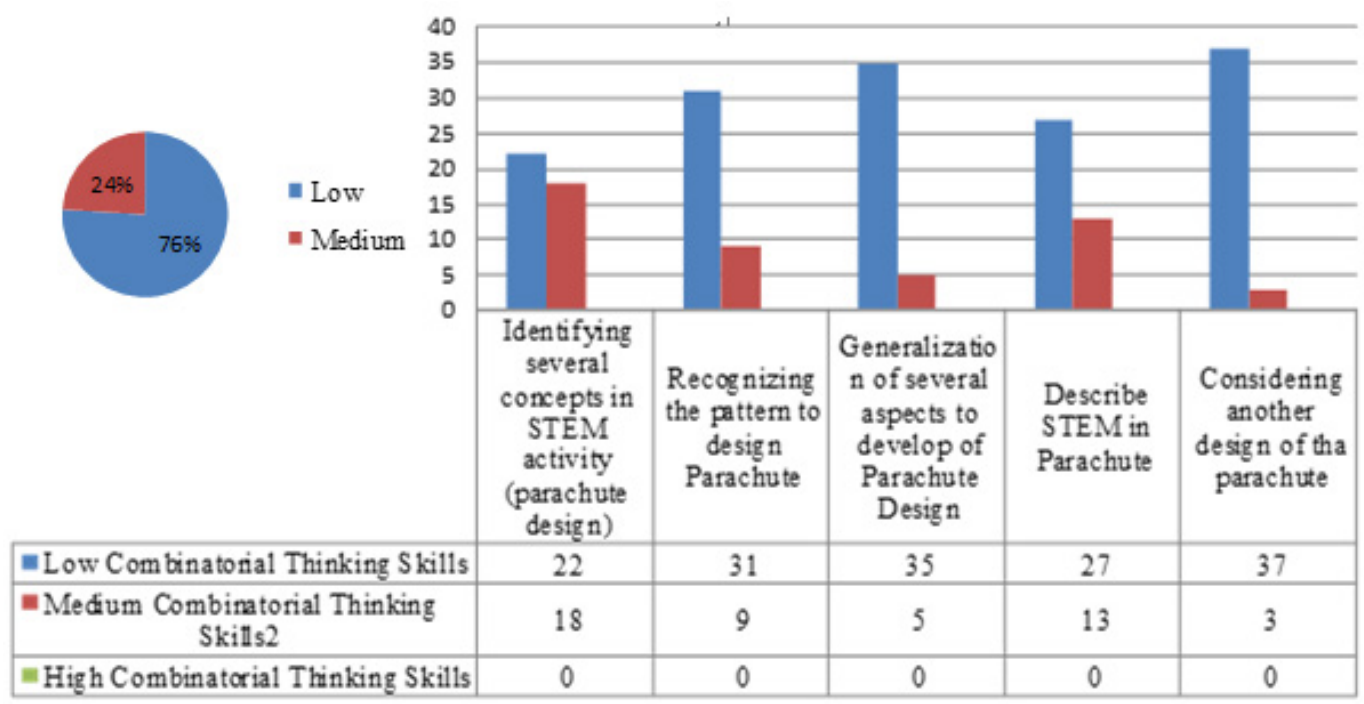

Figure 5. Distribution combinatorial Thinking Skills in Control Class in pre-test result

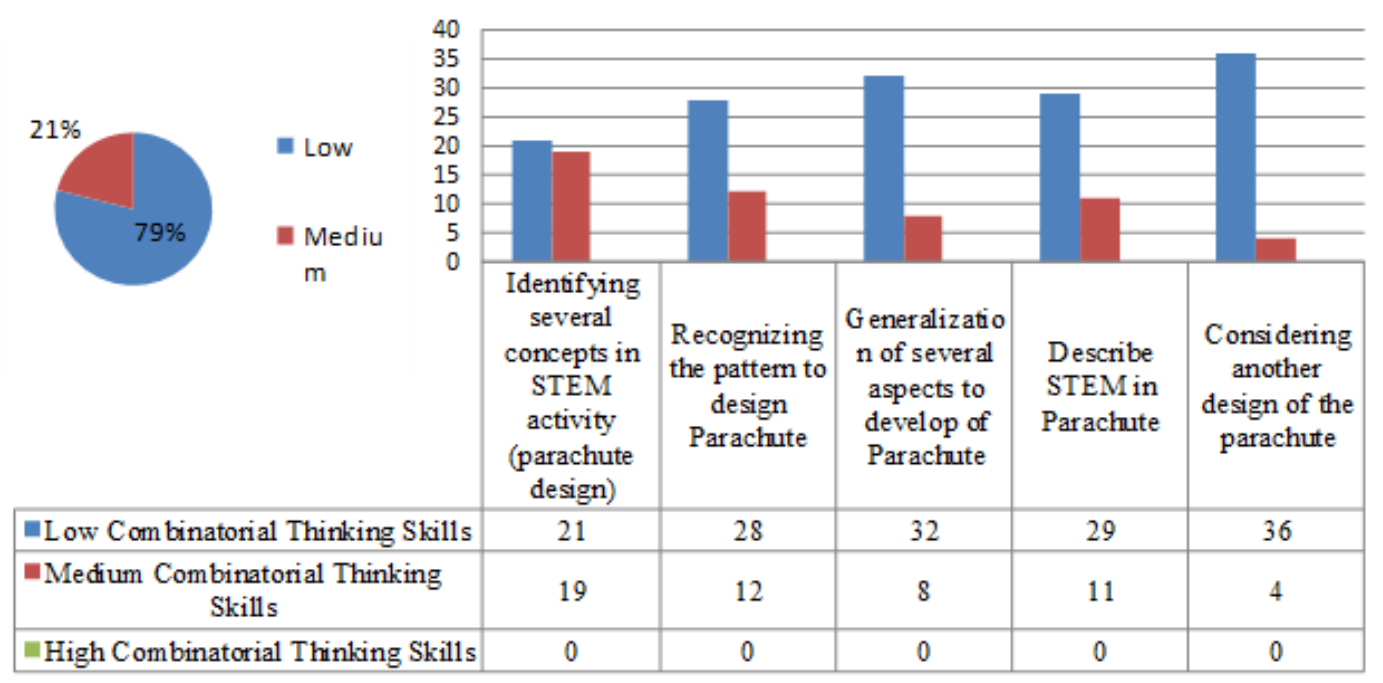

Figure 6. Distribution combinatorial Thinking Skills in Experimental Class in pre-test result 


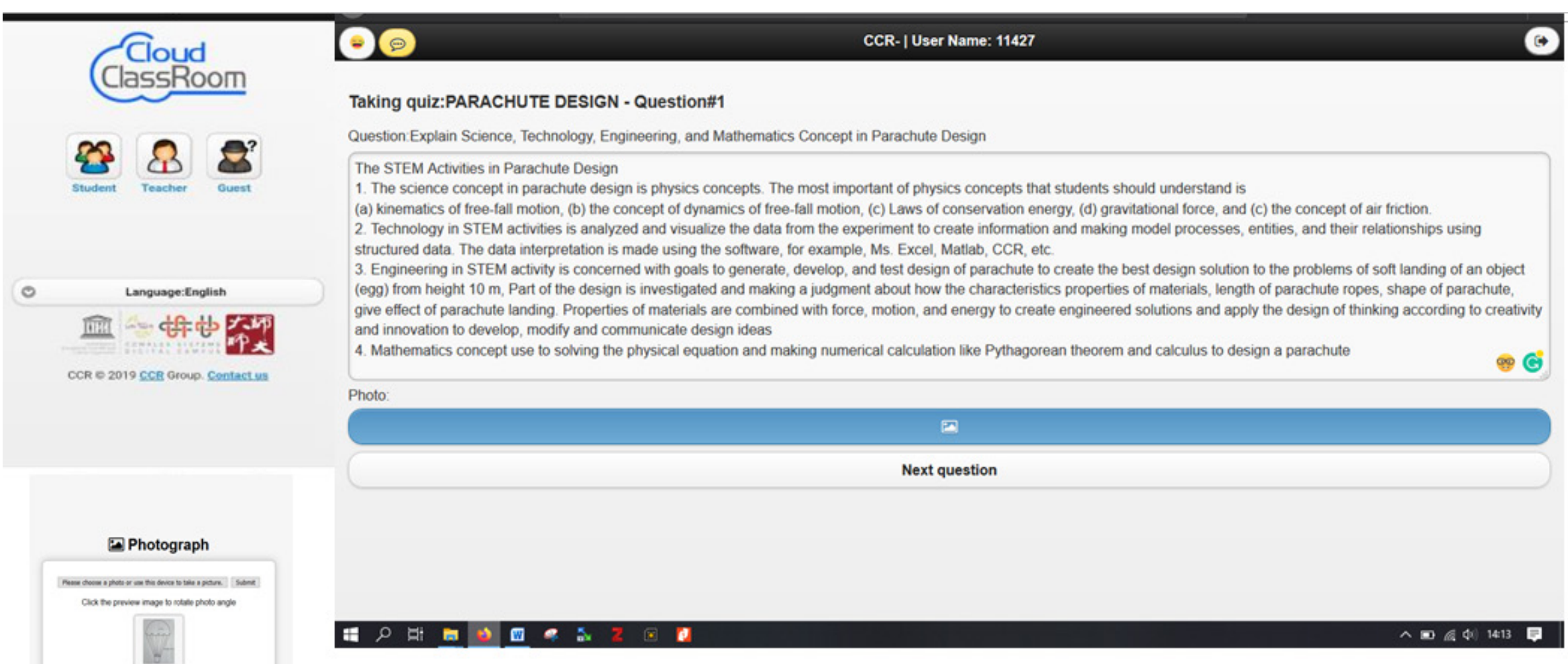

Figure 7. Cloud Classroom (CCR) interface 
In traditional teaching, only the direct instruction method was used in the teaching and learning process. In traditional teaching and learning style, the student is only listening and writing explanation from lecturer without any exciting activity. And now in 21 century, we are integrating teaching and learning process helped by CCR (Cloud Classroom) as an interactive website written in HTML and working in every internet device likes smartphone, PDA, computer and laptop, the interface of CCR shown on Figure 7. It facilitates integration between lecturer and student with several features such as text response, emoticon, a multimedia presentation from CCR database, uploading a picture, sharing link videos from youtube [19]. This study used CCR to carry out student achievement tests according to the combinatorial thinking category. Lecturer design integration between real class and CCR as flipped classroom swapping research work into classwork. Analysis of content and information supported STEM was also included in the first step to know how deep the student and teacher will do the learning and research activity in one condition. This activity depends on student-centered learning and by using CCR student and lecturer have much time to discuss the topics of research. CCR is efficient to carry out the formative assessment (pretest and posttest). Using CCR lectures could make some questions according to combinatorial thinking criteria and upload questions as open-ended questions.

The result of the post-test score after implementation RBL integrated with CCR shows in Figure 8 and Figure 9 that percentages of combinatorial thinking students in control class and experimental class are increasing. In Control class, combinatorial thinking skills in low category reach $16 \%$, medium $39 \%$, and high $45 \%$.

The result shows in experimental class there is $13 \%$ at the low level of combinatorial thinking, $36 \%$ on the medium level, and $51 \%$ at a high level. According to this data, implementation of combinatorial thinking methods integrated with $\mathrm{CCR}$ is very useful to improve combinatorial thinking skills in parachute design.
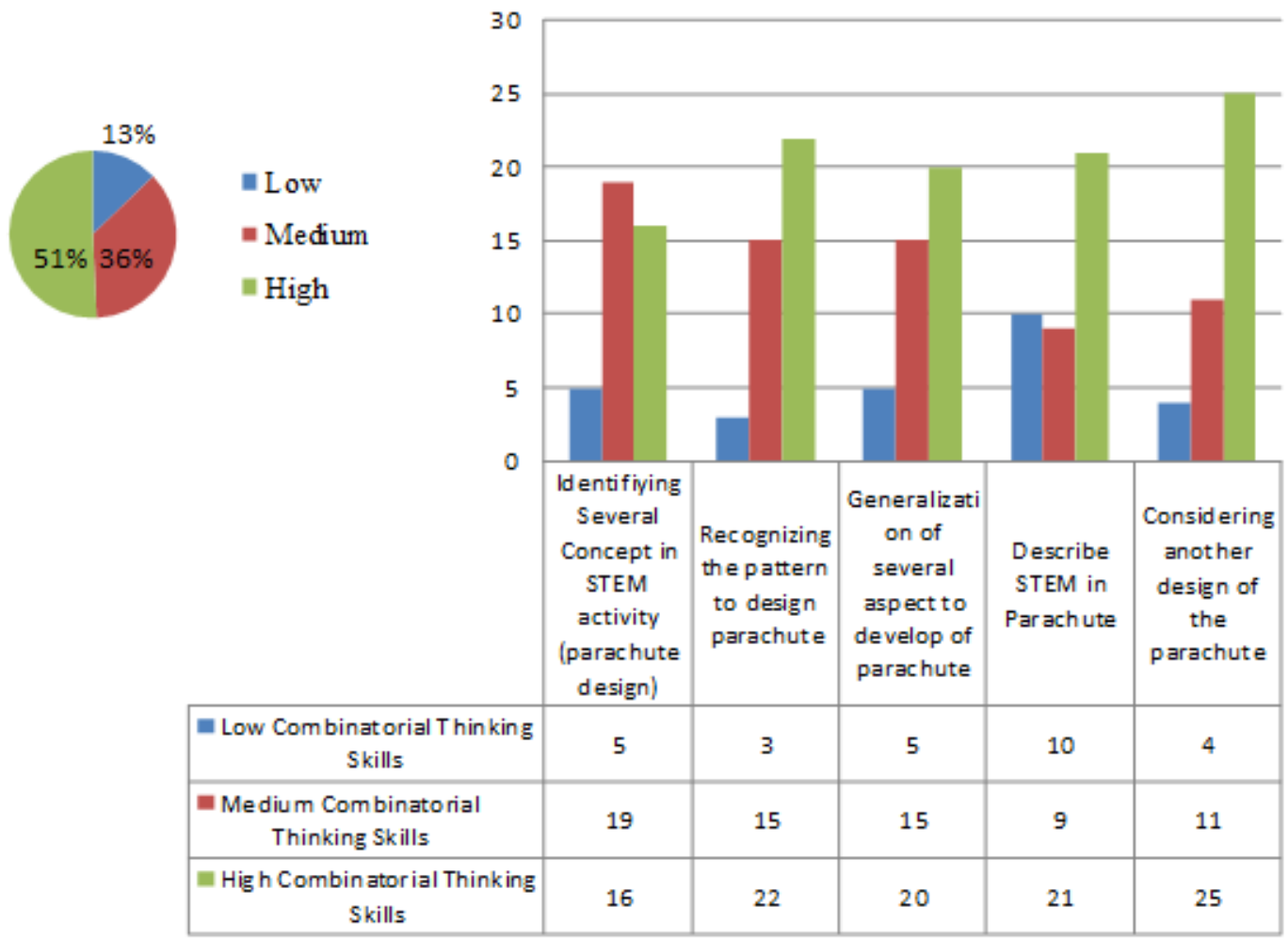

Figure 8. Distribution combinatorial Thinking skills in Experimental Class After implementation RBL 


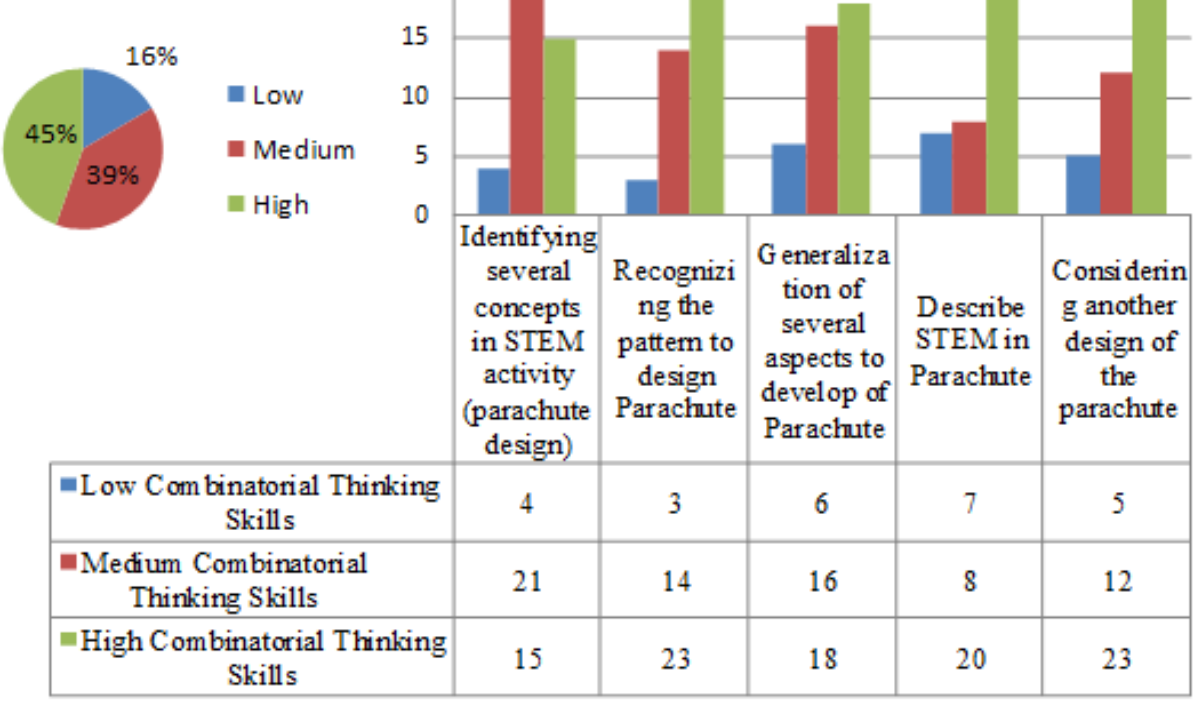

Figure 9. Distribution combinatorial Thinking Skills in Control Class After implementation RBL

Table 6. Combinatorial Thinking Skills in STEM activity (Parachute Design)

\begin{tabular}{|l|l|}
\hline Indicator & Sub-Indicator \\
\hline $\begin{array}{l}\text { A. Identifying several concepts } \\
\text { in STEM activity (parachute } \\
\text { design) }\end{array}$ & $\mathrm{A}_{1}$ Find the science concept in parachute design \\
$\mathrm{A}_{2}$ Find the technology which applied parachute design \\
$\mathrm{A}_{3}$ Find the engineering process in parachute design \\
$\mathrm{A}_{4}$ Find the mathematics concept in parachute design
\end{tabular}


Analysis of Student combinatorial thinking Skills is divided into three categories (low, medium, and high) from observation result (STEM activity) and post-test score. The researcher takes three student's working tests as a sample to indicated three categories that show student combinatorial thinking skills; each student explains each level. The first work is a low combinatorial thinking level; second is medium combinatorial thinking skills and third is high combinatorial thinking skills. Table 6 shows five indicators and sub-indicator of combinatorial thinking skills in a STEM activity.

The first worksheet shows students collecting information about parachute design in implementation in a STEM activity. After that, interviews were conducted to find out the portrait phase of the students' way of thinking.

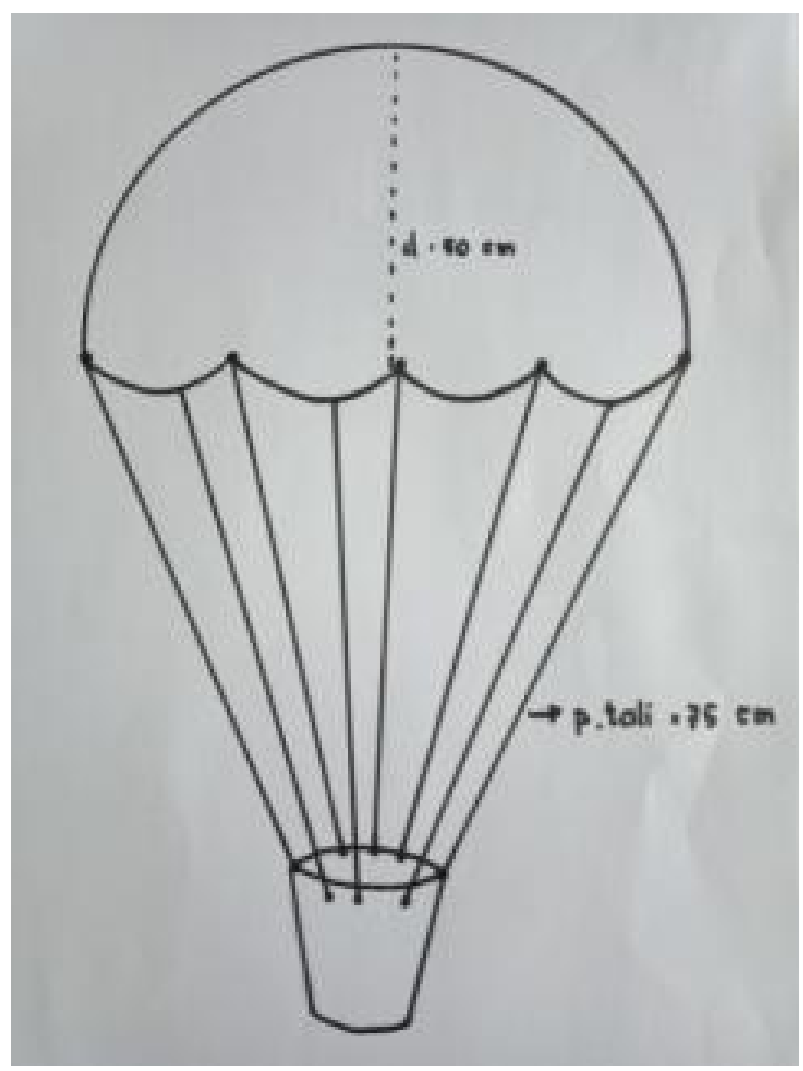

Interview is made with the students in this category of combinatorial thinking from exploration steps of student tasks and making graphs to getting the student portrait phase. The student only performs minimum steps from all of the indicators categorize in low combinatorial thinking skills. The student only performs $\mathrm{A}_{1}$ (Finding the science concept in parachute design), $\mathrm{A}_{2}$ (Finding the technology which applied parachute design), jump into $B_{1}$ (Selecting material for parachute), $C_{1}$ (Condition of egg), $C_{2}$ (Landing in softly), jump into $\mathrm{D}_{1}$ (Explaining and analyzing the science concept in parachute design), $\mathrm{D}_{2}$ (Explaining and analyzing which applied parachute design), and the last steps is $\mathrm{E}$ (Considering another design of the parachute). A student worksheet is shown in Figure 10, and Figure 11 is a portrait phase.
Science behind parachutes

a. Gravity

Gravity is the attraction that occurs between all particles that have mass in the universe

b. Air resistance

Air is a mixture of gasses that exist in the layers that are issued by the earth

c. Wind speed

This wind speed will affect the slow launch of the parachute which will be dropped from a height. This strong wind can also make the parachute imbalace when deployed.

Figure 10. Student worksheet (Low Combinatorial Thinking Category 


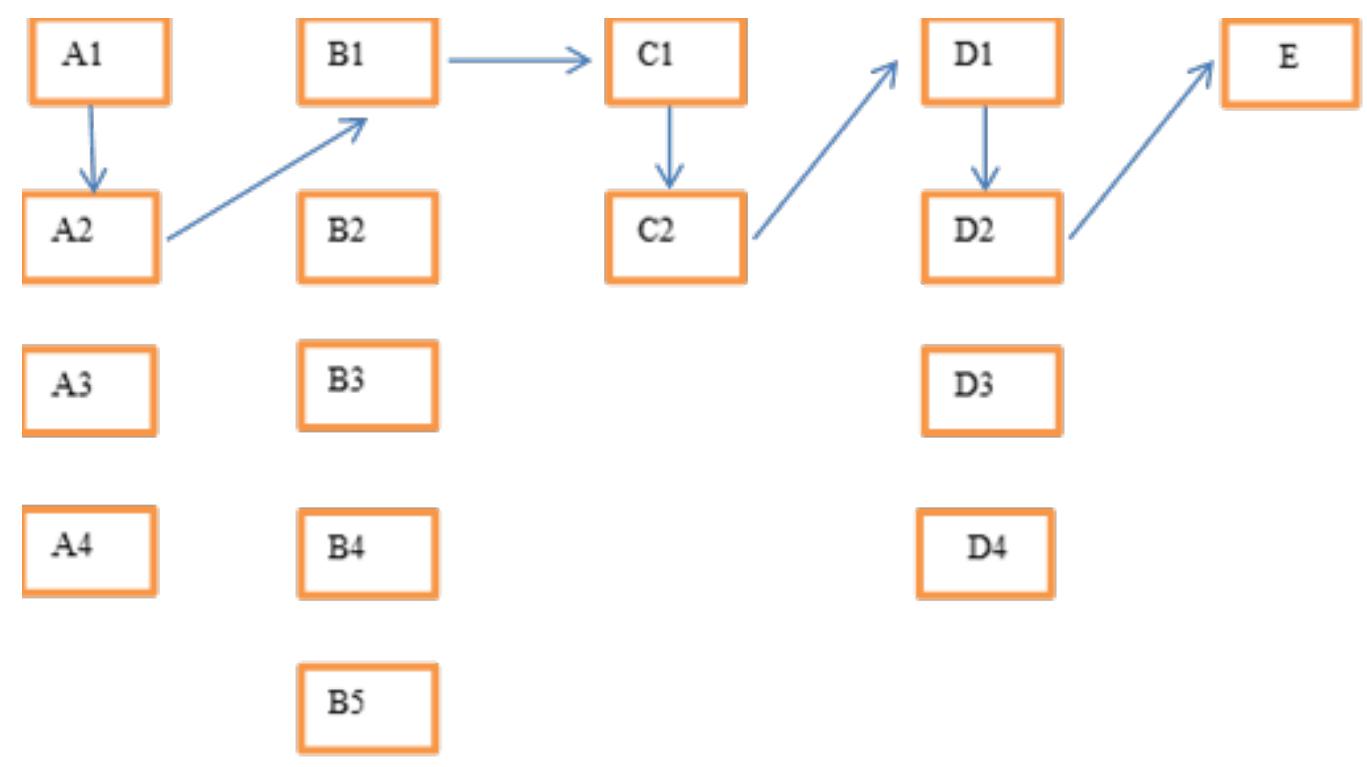

Figure 11. Student portrait phase (Low Combinatorial Thinking Category)

The second worksheet shown in Figure 12 is medium combinatorial thinking skills. The portrait phase of student (Figure 13) starts from $A_{1}$ Finding the science concept in parachute design, $A_{3}$ Finding the engineering process in parachute design, $B_{2}$ Selecting the shape of parachute, $B_{1}$ Selecting material for parachute, $\mathrm{B}_{4}$ Selecting the length of parachute, $\mathrm{B}_{5}$ Selecting the materials to save the load (egg), $\mathrm{C}_{1}$ Condition of egg, $\mathrm{C} 2$ (Landing in softly), $\mathrm{D}_{3}$ Explaining and analyzing the engineering process in parachute design, $\mathrm{E}$ (Considering another design of the parachute).

Science behind parachutes

\section{a. Gravity}

Gravity is the attraction between all particles that have a mass in the universe. The presence of gravity cause a gravitational field.

\section{b. Air resistance}

Air resistance is the effect of delay by air obtained from objects when moving through the atmosphere. The cause of air resistance is the collision of objects in solid objects with atmospheric gas molecules. The greater the number of air molecules the greater the resistance.

\section{c. Collision}

In this parachute design collision concept can occur when after collision objects stick together or there is no reflection at all.

\section{d. Freefall}

Freefall motion is one straight in one dimension which is only influenced by the presence of gravitational force.



Figure 12. Student worksheet (Medium Combinatorial Thinking Category) 




Figure 13. Student portrait phase (Medium Combinatorial Thinking Category)

The third worksheet shown in Figure 14 is high combinatorial thinking skills. The portrait phase of student (Figure 15) starts from $A_{1}$ Finding the science concept in parachute design, $A_{2}$ Finding the technology which applied parachute design, $\mathrm{A}_{4}$ Finding the mathematics concept in parachute design, $A_{3}$ Finding the engineering process in parachute design, $B_{1}$ selecting material for parachute, $B_{2}$ selecting the shape of a parachute, $B_{4}$ select the length of parachute, $B_{3}$ Selecting the number of the parachute (single/double), $\mathrm{B}_{5}$ selecting the materials to save the load (egg), $\mathrm{C}_{1}$ Condition of egg, $\mathrm{C}_{2}$ Landing in softly, $\mathrm{D}_{1}$ Explaining and analyzing the science concept in parachute design, $\mathrm{D}_{4}$ Explaining and analyzing the mathematics concept in parachute design, $\mathrm{D}_{3}$ Explaining and analyzing the engineering process in parachute design and the last steps is $\mathrm{E}$ (Considering another design of the parachute).

Change velocity per unit time is called acceleration mathematically express:

$$
a=\frac{v_{t}-v_{0}}{t_{t}-t_{0}}=\frac{\Delta v}{\Delta t}
$$

For free-fall motion, the acceleration is the acceleration due to gravity (g), the equation of the form:

$$
v_{t}=v_{0}+g t
$$

Free falling motion effect

$$
h=\frac{1}{2} g t^{2}
$$

1. Wide of the octagon (Big parachutes)

The side of the octagon is $32 \mathrm{~cm}$. So, the wide of the octagon is

$$
A=(2+2 \cdot \sqrt{2}) \cdot 32=4944,3 \mathrm{~cm}^{2}
$$

2. Wide of circle parachute

The diameter of the pie is $16 \mathrm{~cm}$. So, the wide pie is

$$
A=\frac{1}{4} \pi 16^{2}=200,96 \mathrm{~cm}^{2}
$$

3. The wide of the parachute (octagon and circle)

$$
A=4944,3+200,96=5145,26 \mathrm{~cm}^{2}
$$



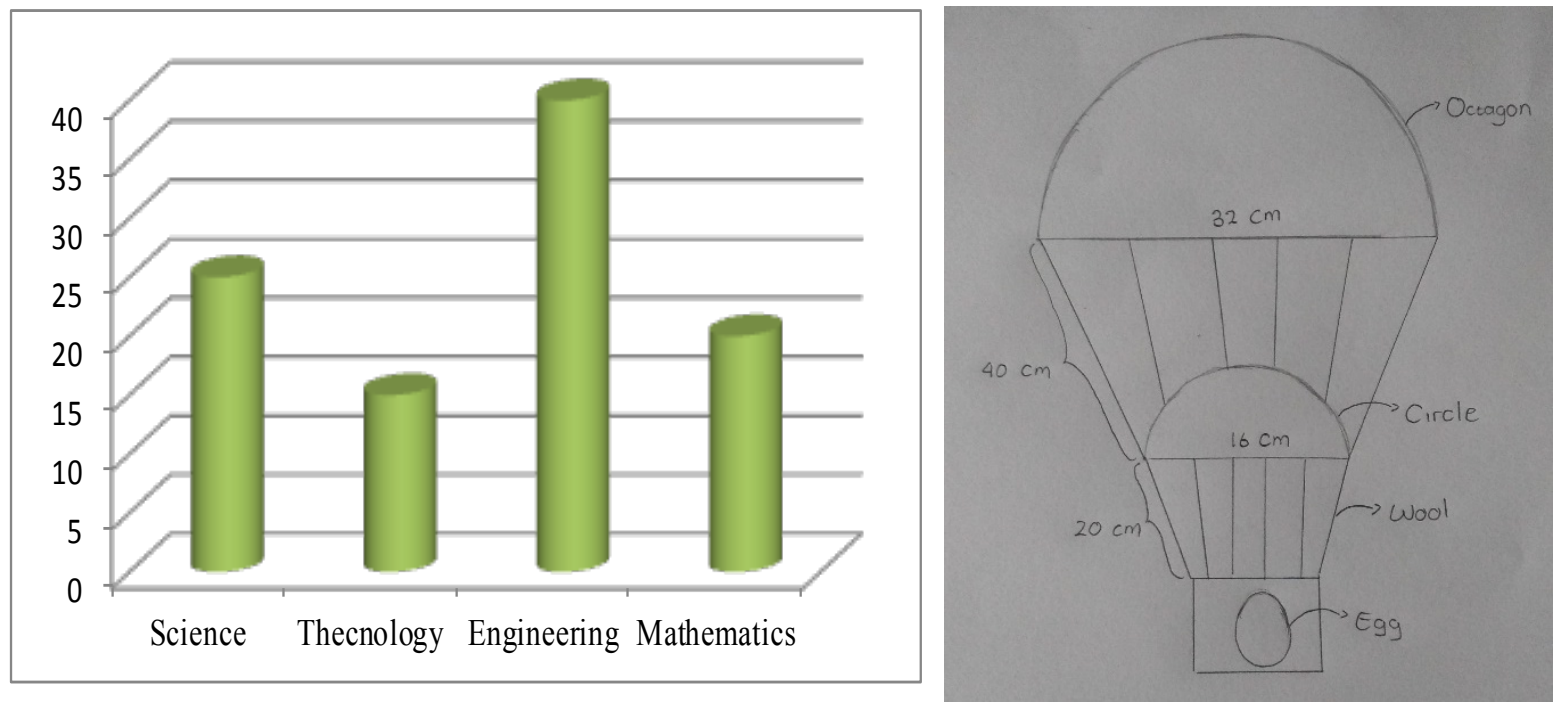

Figure 14. Student worksheet and parachute design (High Combinatorial Thinking Category)

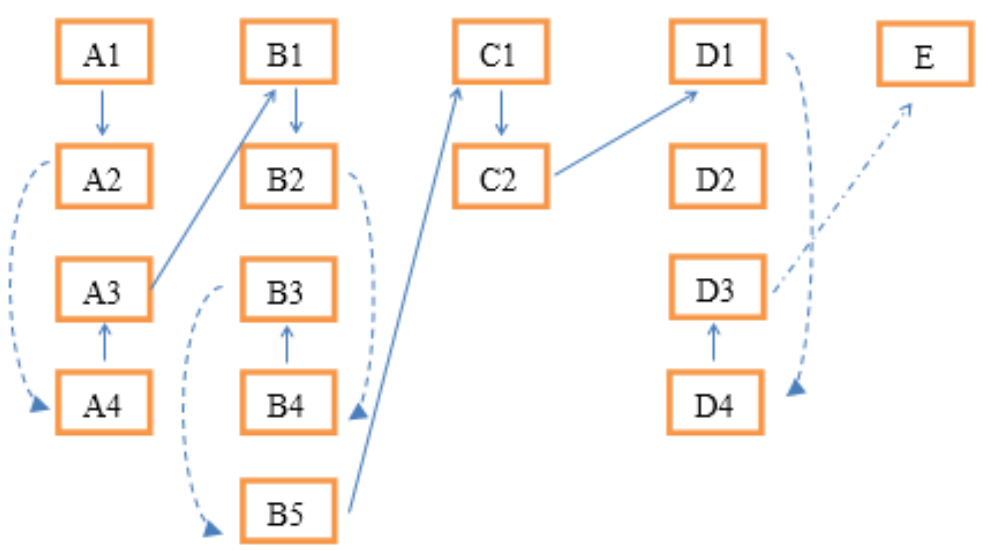

Figure 15. Student Portrait Phase (High Combinatorial Thinking Category)

Student oral presentation is one of the important activities to express their level of knowledge about STEM concepts in parachute design activity. We create eight groups in the Experiment class and control. Each group consists of 5 students. Finally, to know students' knowledge and perception about the implementation of research-based learning in parachute design after the presentation process, the students were interviewed with several questions according to parachute design content. The data obtained from interviews are discussed below by the teacher and student.

Teacher: Is this excited about design parachute, what is a new experience in this course?

Student: Yes, it's very exciting, a new experience in this course is I analyze all of the factors to design parachute integrated with science, mathematics and technology as well as engineers.

Teacher: What is the science concept in parachute design?

Student: Force from newton laws, momentum, gravitational force, the law of conservation energy, and air resistance.

Teacher: In mathematics, what is the main concept to design parachute?

Student: It's about the measure of circle area of a parachute.

Teacher: What is the integrated technology used in parachute design?

Student: I'm using the Internet to get information about the effective design of parachute.

Teacher: How to make egg more safely from the landing process?

Student: I use styrofoam to protect the egg.

Teacher: What about your design of parachute? With a single or double parachute?

Student: I'm using the double parachute because a double parachute is more stable than a single parachute. This is related to air resistance.

\subsection{Discussion}

This research explores the effectiveness of the 
implementation model of teaching Research-Based Learning in improving combinatorial thinking skills in STEM activity to design parachute. The finding of this research indicates that students in the experimental class had a positively significant impact on the implementation of the Research-Based Learning model. This can be seen from an increase in students' combinatorial thinking skills after implementing the RBL. The result is in line with that of Suntusia (2019), Ridlo (2019) and Hastuti et al (2019) showing that the implementation of RBL making the student more critical and creative than student taught with traditional methods. Implementation of RBL also appropriate with Sota \& Peltzer (2017) states implementation of RBL improve knowledge, competence, cognitive skills, and information technology skills. This research used a cloud classroom for student assessment for pretest and posttest. CCR also had a positive impact on the improvement of student knowledge because CCR facilitates student and lecturer in the online classroom and online assessment process. The integration of CCR in the learning process can help teachers to reduce teaching load, and they can use class time to cover more relevant topics (Liou, 2016). The online assessment using a cloud classroom to facilitate students using a menu, direct question, and quiz. The lecturer can provide interaction with a student, and student can express emotion by using an emoticon, The result of simulation from computer programming is upload by using CCR, and the advantages of using CCR are swapping research work into classwork.

The combinatorial thinking skills from the experimental class were higher compared with those in the control class. The result indicates student post-test result which means the experimental class score were significant value and better than control class, because in experimental class learning activities used research-based learning which directed student to integrate learning and research in one condition. The impact of research-based learning on students has improved their capability to analyze, recognize the information to design parachute in a STEM activity, and get a new design of parachute by using new information from the previous information and STEM experiment, development information, and using mathematical methods to analyze each factor in parachute design. RBL facilitates students and teachers to apply research in class and strengthen the academic atmosphere of relationship between teaching and research [20]. Through the Implementation of RBL, the student can make a new design of parachute in improving combinatorial thinking skills.

\section{Conclusions}

This research result implies that implementation of the research-based learning model in STEM activity (parachute design) is effective than the traditional teaching model. Implementation of the Research-Based Learning (RBL) model makes students more creative in making a new design of parachute with several combinations of materials, string, shape, and number of parachutes. This is because the implementation of RBL provides student with research atmosphere in a learning activity with development capability in science, mathematics, and technology capability. Cloud Classroom also gives a positive effect on student assessment in STEM activities. In the future, we wish to examine the effect of RBL integrated with CCR at a different section of the STEM project.

\section{Acknowledgements}

We gratefully acknowledge the support from CEREBEL Research Group 2019, Faculty of Teacher Training and Education- University of Jember.

\section{REFERENCES}

[1] Hastuti, Y., Dafik, \& Hobri. The analysis of students combinatorial thinking skill based on their cognitive style under the implementation of research-based learning in the total rainbow connection study. Journal of Physics, Vol. 1211, No.012088, 2019.

[2] Monalisa, L. A., Dafik, Hsatuti, Y., Hussen, S., \& Oktavianingtyas, E. The implementation of research-based learning in developing the students mathematical generalization thinking skills in solving a paving blocks design problems. Journal of Physics, Vol. 243, No. 012168 , 2019.

[3] Dafik. Developing and Research Based Curriculum for Higher Education. Universitas Jember, Jember, 2016.

[4] Septory, B. J., Dafik., \& Tirta, I. M. The analysis of students' combinatorial thinking skills in solving r-dynamic vortex coloring under the implementation of problem-based learning. Journal of Physics, Vol. 1211, No. 012084, 2019.

[5] Ridlo, Z. R., Prihandini, R. M., Nugroho, C. I. W., \& Alfarisi, R. The effevtiveness of research-based learning with computer programming and highly interactive cloud classroom (HIC) elaboration in improving higher order thinking skills in solving a combination of wave functions. Journal of Physics, Vol. 1211, No. 012049, 2019.

[6] Dafik, Sucianto, B., Irvan, M., \& Rohim, M. A. The analysis of student metacognition skills in solving rainbow connection problem under the implementation of research-based learning model. International Journal of Instruction, Vol.12, No. 4, 2019.

[7] Hussen, S., Dafik, Monalisa, L. A., Murtikusuma, R. P., \& Oktavianingtyas, E. Combinatorial thinking and creativity skills in soving a colored-square paving decoration problem. Journal of Physics, Vol. 1211, No. 012062, 2019.

[8] Robert, T., Jackson, C., Schroeder, M. J. M., Bush, S. B., 
Maiorca, C., Cavalcanti, M., Schroeder, D. C., Delaney, A., Putnam, L., \& Cremeans, C. Students' perceptions of STEM learning after participating in a summer informal learning experience. International Journal of STEM Education, Vol. 5, No. 35, 2018.

[9] Moore, T.J. STEM integration: Crossing disciplinary borders to promote learning and engagement. Invited presentation to the faculty and graduate students of the UTeachEngineering, Uteach Natural Sciences, and STEM Education program area at University of Texas at Austin, 2008.

[10] Srikoon S, Bunter T, Samranjai J, Wattanathorn J. 2014 Social and Behavioral Science, Vol. 116, No. 913-917, 2014.

[11] Usmeldi. The effectiveness of research-based physics learning module with predict-observe-explain strategies to improve the students competence. Journal of Physics, Vol. 1013, No. 012041, 2018.

[12] Dini, R. P., Dafik, \& Slamin. The analysis of generalization thinking skills on solving local super $H$-decomposition antimagic total coloring regarding the application of research-based learning. Journal of Physics. Vol. 1211, No. 012080, 2019.

[13] Rohim, M. A., Dafik, Slamin., \& Sucianto, B. The analysis of implementation of research-based learning implementation in developing the students' creative thinking skill in solving dominating set problem. Journal of Physics, Vol. 243, No. 012143, 2019.

[14] Capraro, M. M., Whitfield, J. G., Etchells, M. J., \& Capraro, R. R. A companion to interdisciplinary STEM project-based learning. https://doi.org/10.1007/978-94-6300-485-5.

[15] Budayawati, L. P. I., Jovanska, V., Fitriyah, S., \&Final, Z. The analysis of the implementation of research-based learning to improve students' critical thinking skills based on theircognitive style. Journal of Physics, Vol. 243, No. $012169,2019$.

[16] Tsupros, N., Kohler, R., \& Hallinen, J. STEM education: A project to identify the missing components. Intermediate Unit 1: Center for STEM Education and Leonard Gelfand Center for Service Learning and Outreach. Caenegie Mellon University, Pennsylvania, 2009.

[17] National Research Council (NRC). Improfing undergraduate instruction in science technology, engineering, and mathematics. Washington, DC: National Academy Press, 2003.

[18] Sugiyono. Metode penelitian Pendidikan (kuantitatif, kualitatif, kombinasi, R\&D dan penelitian Pendidikan). Bandung: Alfabeta press, 2017.

[19] Chien, Y. T \& Chang, C. Y. Supporting socio-scientific argumentation in the classroom throught automatic group formation based on students's real time response. In: Khine MS (ed) Science Education in Easr Asia: Pedagogical innovations and research informed practices, Springer, Berlin. 2015.

[20] Schapper, J., \& Mayson, S. E. Research-led Teaching: Moving from a Fractured Engagement to a Marriage of Convenience. Higher Education Research \& Development,

$$
\text { 29, 641-651, } 2010 .
$$

[21] Suntusia, Dafik, \& Hobri, The Effectiveness of Research Based Learning in Improving Students' Achievement in Solving Two-Dimensional Arithmetic Sequence Problems, International Journal of Instruction, 12/1. 2019

[22] Sota, C., \& Karl, P. The Effectiveness of Research Based Learning among Master degree Student for Health Promotion and Preventable Disease, Faculty of Public Health, Khon Kaen University, Thailand. Procedia-Social and Behavioral Sciences, 237, 1359-1365, 2017. 2017. 